\title{
Tumor response and outcome after reverse treatment for patients with synchronous colorectal liver metastasis: a cohort study
}

\author{
Céline Du Pasquier ${ }^{1,3+}$, Didier Roulin ${ }^{1,3+}$, Pierre Bize ${ }^{2}$, Christine Sempoux $^{3}$, Caterina Rebecchini ${ }^{3}$,
} Michael Montemurro ${ }^{4}$, Markus Schäfer ${ }^{1}$, Nermin Halkic ${ }^{1}$ and Nicolas Demartines ${ }^{1 *}$

\begin{abstract}
Background: The reverse treatment of patients with synchronous colorectal liver metastases (CRLM) is a sequential approach with systemic chemotherapy first, followed by liver resection, and finally, primary tumor resection. The aim of this study was to assess the feasibility, the radiological and pathological tumor response to neoadjuvant therapy, recurrence rates and long-term survival after reverse treatment in a cohort study.

Methods: Data from patients with CRLM who underwent a reverse treatment from August 2008 to October 2016 were extracted from our prospective hepato-biliary database and retrospectively analyzed for response rates and survival outcomes. Radiological tumor response was assessed by RECIST (Response Evaluation Criteria In Solid Tumor) criteria and pathological response according to TRG (Tumor Regression Grade). Disease-free and overall survival were estimated with Kaplan-Meier survival curves.

Results: There were 44 patients with 19 rectal and 25 colonic tumors. The reverse treatment was fully completed until primary tumor resection in 41 patients (93\%). Radiological assessment after chemotherapy showed $61 \%$ of complete/partial response. Pathological tumor response was major or partial in 52\% of patients (TRG 1-3). Median disease-free survival after primary tumor resection was 10 months ( $95 \% \mathrm{Cl}$ 5-15 months). Disease-free survival at 3 and 5 years was $25 \%$ and $25 \%$, respectively. Median overall survival was 50 months ( $95 \% \mathrm{Cl} 42-58$ months). Overall survival at 3 and 5 years was $59 \%$ and 39\%, respectively.

Conclusion: The reverse treatment approach was feasible with a high rate of patients with complete treatment sequence and offers promising long-term survival for selected patients with advanced simultaneous colorectal liver metastases.
\end{abstract}

Keywords: Colorectal liver metastases, Reverse treatment, Liver-first, Liver surgery, Neoadjuvant chemotherapy

\footnotetext{
* Correspondence: demartines@chuv.ch

This study was presented in parts at:104 $4^{\text {th }}$ Swiss Congress of Surgery, Bern, Switzerland, May 31 - June 2, $2017119^{\text {th }}$ French Congress of Surgery, Paris, France, $29^{\text {th }}$ September 2017

${ }^{+}$Céline Du Pasquier and Didier Roulin contributed equally to this work. 'Department of Visceral Surgery, Lausanne University Hospital (CHUV), University of Lausanne, Rue du Bugnon 46, 1011 Lausanne, Switzerland Full list of author information is available at the end of the article
}

(C) The Author(s). 2020 Open Access This article is licensed under a Creative Commons Attribution 4.0 International License, which permits use, sharing, adaptation, distribution and reproduction in any medium or format, as long as you give appropriate credit to the original author(s) and the source, provide a link to the Creative Commons licence, and indicate if changes were made. The images or other third party material in this article are included in the article's Creative Commons licence, unless indicated otherwise in a credit line to the material. If material is not included in the article's Creative Commons licence and your intended use is not permitted by statutory regulation or exceeds the permitted use, you will need to obtain permission directly from the copyright holder. To view a copy of this licence, visit http://creativecommons.org/licenses/by/4.0/ The Creative Commons Public Domain Dedication waiver (http://creativecommons.org/publicdomain/zero/1.0/) applies to the data made available in this article, unless otherwise stated in a credit line to the data. 


\section{Background}

At the time of diagnosis, up to $20 \%$ of patients with colorectal cancer have simultaneous liver metastases [1]. In addition to treat the primary tumor, complete resection of colorectal liver metastases (CRLM) is mandatory to provide a curative treatment [2]. Development of new anti-cancer drugs and their combination with anti-VEGF and/or anti-EGFR agents increased the major tumor response rate up to $72 \%$ [3-7], thus offering to new treatment strategies. High response rates to chemotherapy offer the potential of curative treatment after downsizing CRLM for patients with initial unresectable disease. The traditional treatment ("classic") consists in a staged approach with resection of the primary colorectal tumor, followed by systemic chemotherapy and liver resection.

The reverse treatment or liver-first approach, first described by Mentha in 2006, was based on initial neoadjuvant chemotherapy, followed by liver resection and finally, primary tumor resection [8]. The rationale of this strategy was to target liver metastases first, thus avoiding their progression during treatment of the primary tumor, especially for patients with multiple or large CRLM. The precise selection criteria for choosing classical or reverse strategies were not clearly defined, and none of these have until now shown any survival advantage [9]. The reverse treatment approach has been used at our institution since 2008 . The study aim was to assess the feasibility and completion rate of liver-first treatment, radiological and pathological tumor response to neoadjuvant chemotherapy, as well as overall and disease-free survival.

\section{Methods}

\section{Study design}

Retrospective analysis of prospectively collected data on consecutive patients who underwent liver resection for CRLM within a reverse treatment at our institution from August 2008 to October 2016. Selection criteria for reverse treatment was synchronous CRLM with predominant hepatic disease with no bowel occlusion at initial presentation as evaluated and validated during multidisciplinary tumor board. Exclusion criteria for a liver-first approach were: metastases not located in the liver or lung, persistent unresectable liver metastases after neoadjuvant chemotherapy, and more than 3 pulmonary metastases. Patients with refusal of consent were not included and written consent was obtained for all participants.

This study was approved by the local ethical committee (2016-01286) and conducted in accordance with the STROBE criteria (http://strobe-statement.org/).

\section{Treatment strategy}

A reverse treatment was defined as sequential management with neoadjuvant chemotherapy, hepatic resection, and then resection of the primary colorectal cancer. Following neoadjuvant chemotherapy, radiological reassessment with contrast-enhanced CT and/or liver MRI was performed after 2 to 6 cycles of treatment to evaluate the response of CRLM according to the response evaluation criteria in solid tumors (RECIST) [10]. Liver resections were performed by experienced hepatobiliary surgeons with curative intent. Intraoperative ultrasound was used to guide the resection. Primary tumors were resected after complete hepatic clearance. In case of pulmonary metastases, they were treated after hepatic and primary tumor resection. The need for adjuvant chemotherapy was discussed at our multidisciplinary tumor board. The oncological follow-up was carried out by oncologists or surgeons, with at least monitoring of CEA, thoraco-abdominal CT every 3 months for the first year, and then every 6 months and liver MRI every 6 months.

\section{Outcome measures}

Postoperative complications within 30 postoperative days were prospectively collected in our hepatobiliary and colorectal databases. Mortality was assessed after 30 and 90 postoperative days. The Clavien classification [11], grading the most severe complication of each patient, and the Comprehensive Complication Index (CCI) [12], an index calculated by adding each complication weighted for its severity, were reported. Major complications were defined as Clavien grade 3 or 4 .

Radiological response to neoadjuvant treatment according to RECIST criteria was systematically reevaluated by a senior radiologist (PB). Pathologic data were independently re-analyzed for purpose of the present study by two pathologists, one senior with gastrointestinal and hepatobiliary expertise (CS) and one junior involved in gastro-intestinal and hepatobiliary pathology (CR). All archival slides (from formalin-fixed paraffin-embedded tissue) were reviewed, blinded from the rest of the study. Forty-four cases were analyzed, from which four consultation cases and three local cases had no colorectal resection material available.

For the liver metastasis specimens, tumor regression grade (TRG) was assessed in each metastasis according to Rubbia-Brandt [13]. Non-tumoral liver parenchyma was analyzed to define the presence of chemotherapy associated liver injury. The presence of sinusoidal obstruction syndrome (SOS) was graded according to Rubbia-Brandt [14]. The presence of steatosis and steato-hepatitis was evaluated and fibrosis was graded according to the METAVIR score [15].

For the colorectal resections specimens, TRG was assessed according to Mandard (TRG 1 to 5, with TRG 1 corresponding to complete regression with absence of histologically identifiable residual cancer and fibrosis) [16]. In the peri-tumoral region, the amount of fibrosis 
and inflammation was evaluated in 3 grades (1: low; 2: moderate 3: abundant). For patients with multiple liver metastases and different TRG, the worse metastasis (lowest response) was used for TRG categorization [13].

\section{Follow-up method}

Follow-up was made on a medical chart basis. In case of missing data due to outwards follow-up of the patient, the treating oncologist was contacted by mail for an update. Disease-free survival (DFS) was calculated from the day of the primary cancer resection. Overall survival (OS) was calculated from the day of the primary diagnosis.

\section{Statistical analysis}

Categorical variables were reported as numbers and percentages, while continuous variables were reported as medians and interquartile ranges for non-normally distributed data, or means and standard deviations for normally distributed data. DFS and OS were calculated with the Kaplan-Meier method. Statistical analysis was made with SPSS statistical software package (SPSS version 23 for windows, SPSS inc., Chicago, IL, USA).

\section{Results}

\section{Patients' characteristics and treatment modalities}

A total of 44 patients underwent liver resection in the setting of reverse treatment; demographics and characteristics are shown in Table 1. Most patients (33/44, $75 \%$ ) initially had unresectable CRLM, as assessed by HPB surgeons based on location, size of metastasis and Future Remnant Liver calculation (FRL).

Chemotherapy regimen were decided by the referring oncologist on an individualized basis. Patients received a median of six cycles (range 2-12) of neoadjuvant chemotherapy, Oxaliplatin or Irinotecan-based (13 FOLFOX, 15 FOLFIRI, 4 FOLFIRINOX, 4 XELOX, 8 OCFL), with adjunction of anti-VEGF antibody (bevacizumab) in 19 patients (43\%) and anti-EGFR antibody (cetuximab) in 16 patients $(36 \%)$. Three patients $(7 \%)$ received both bevacizumab and cetuximab. Thirteen (30\%) patients

Table 1 Preoperative characteristics of patients with synchronous CRLM and selected for a reverse strategy

\begin{tabular}{|c|c|c|c|}
\hline & & $N=44$ & \\
\hline Age $(y$, median $)$ & & 63 & Range 23-78 \\
\hline Gender (M: F) & & 28: 16 & \\
\hline \multirow[t]{2}{*}{ Primary tumor location } & Colon & 25 & $57 \%$ \\
\hline & Rectum & 19 & $43 \%$ \\
\hline Number of CRLM (median) & & 5 & Range 1-30 \\
\hline Bilobar liver disease & & 30 & $68 \%$ \\
\hline Size of largest CRLM (mm, median) & & 50 & Range 9-151 \\
\hline Initial CEA ( $\mu \mathrm{g} / \mathrm{l}$, median) & & 24.8 & Range $0.6-1300$ \\
\hline
\end{tabular}

CRLM colorectal liver metastasis; CEA carcinoembryonic antigen. were initially treated with palliative chemotherapy and referred to our center because of good response to treatment. Radiological reassessment was performed after a median of 4 cycles of chemotherapy (range 2-6) with chest and abdominal CT scan and liver MRI.

Eighteen patients (41\%) needed portal vein embolization to increase FRL volume. One patient underwent simultaneous hepatic vein and portal vein embolization. For additional small metastases, 11 patients underwent thermoablation (radiofrequency or microwave), either preoperatively $(n=3,6 \%)$, during liver surgery $(n=5,11 \%)$ or both $(n=3,6 \%)$.

Three patients $(7 \%)$ presented pulmonary metastases at the time of diagnosis. Neoadjuvant chemotherapy induced complete response of the lung lesions in 2 patients. The third patient underwent lung wedge resections following resection of the primary tumor.

\section{Liver-first treatment feasibility}

Forty-one out of 44 patients (93\%) completed the treatment until primary tumor resection. The three patients who could not complete the treatment had early metastatic recurrence. The median interval between the end of chemotherapy and liver resection was 5.7 weeks (range: 2.1-19.7 weeks). Longer intervals were seen for patients referred by external oncologists after good response to palliative chemotherapy. For patients who underwent the whole treatment, median interval between liver and colorectal surgery was 9.7 weeks (range: 3.5-34.1 weeks).

Bowel occlusion was experienced by five patients (11\%). Two patients needed tumor stent placement and another two needed diverting stoma because of occlusive symptoms during neoadjuvant chemotherapy. One patient needed a Hartmann's procedure for bowel occlusion after liver resection. Among the 19 patients with rectal tumors, 13 had preoperative radiotherapy: 4 long course $(25 \times 2$ Gy $)$ and 9 short course $(5 \times 5$ Gy) treatments. Twenty-three patients $(52 \%)$ received adjuvant chemotherapy after primary tumor resection.

\section{Liver and colorectal surgeries}

Twenty-seven patients (61\%) underwent major liver resection, involving three or more liver segments (Table 2).

Colorectal surgeries were performed in our institution $(n=33,80 \%)$ or outwards $(n=8,20 \%)$ (Table 2). Colorectal resections were mainly performed by laparoscopy, with 28 laparoscopic approaches (68\%), 9 open surgeries (22\%), and one conversion (2\%) due to adherent status with hepatic laceration during mobilization of the right colon. Data were missing for 3 patients with outwards operations. 
Table 2 Perioperative characteristics and postoperative complications for liver and colorectal resection

\begin{tabular}{|c|c|c|c|c|}
\hline \multirow[t]{2}{*}{ Liver Surgery } & \multirow[b]{2}{*}{ Type of surgery } & \multirow[b]{2}{*}{ Right hepatectomy } & \multicolumn{2}{|c|}{$N=44$} \\
\hline & & & 10 & $23 \%$ \\
\hline & & Left hepatectomy & 6 & $14 \%$ \\
\hline & & $\begin{array}{l}\text { Extended right } \\
\text { hepatectomy }\end{array}$ & 8 & $18 \%$ \\
\hline & & $\begin{array}{l}\text { Extended left } \\
\text { hepatectomy }\end{array}$ & 3 & $7 \%$ \\
\hline & & Sectionectomy & 7 & $16 \%$ \\
\hline & & Bisegmentectomy & 1 & $2 \%$ \\
\hline & & Segmentectomy & 5 & $11 \%$ \\
\hline & & Wedge & 4 & $9 \%$ \\
\hline & $\begin{array}{l}\text { 30-day } \\
\text { complications }\end{array}$ & Minor (Clavien < 3) & 9 & $20 \%$ \\
\hline & & Major (Clavien $\geq 3$ ) & 14 & $32 \%$ \\
\hline & $\begin{array}{l}30 \text { and } 90 \text {-day } \\
\text { mortality }\end{array}$ & & 0 & \\
\hline & $\begin{array}{l}\mathrm{CCl} \text { (median, } \\
\text { range) }\end{array}$ & & 29.3 & $\begin{array}{l}8.7- \\
60.8\end{array}$ \\
\hline & $\begin{array}{l}\text { Liver specific } \\
\text { complications }\end{array}$ & Liver failure & 6 & $14 \%$ \\
\hline & & Biliary leak & 9 & $20 \%$ \\
\hline \multirow[t]{11}{*}{$\begin{array}{l}\text { Colorectal } \\
\text { surgery }\end{array}$} & & & $\begin{array}{l}N= \\
41\end{array}$ & \\
\hline & Type of surgery & Right colectomy & 6 & $15 \%$ \\
\hline & & Left colectomy & 3 & $7 \%$ \\
\hline & & Sigmoidectomy & 12 & $29 \%$ \\
\hline & & $\begin{array}{l}\text { Hartmann's } \\
\text { procedure }\end{array}$ & 1 & $2 \%$ \\
\hline & & Rectal resection & 4 & $10 \%$ \\
\hline & & LAR & 15 & $37 \%$ \\
\hline & $\begin{array}{l}\text { 30-day } \\
\text { complications }\end{array}$ & Minor (Clavien < 3) & 10 & $24 \%$ \\
\hline & & Major (Clavien $\geq 3$ ) & 6 & $15 \%$ \\
\hline & $\begin{array}{l}30 \text { and 90-day } \\
\text { mortality }\end{array}$ & & 0 & \\
\hline & $\begin{array}{l}\mathrm{CCl} \text { (median, } \\
\text { range) }\end{array}$ & & 20.9 & $\begin{array}{l}8.7- \\
83.4\end{array}$ \\
\hline
\end{tabular}

CCI comprehensive complication index; LAR Low anterior resection.

No mortality occurred within 90 days after liver and colorectal surgery.

\section{Radiological and pathological response}

Radiological response to chemotherapy according to the RECIST criteria was mainly partial response $(n=27$, $61 \%)$ or stable disease $(n=12,27 \%)$ (Table 3). One young patient with progressive disease at first evaluation received additional preoperative cycles of chemotherapy, which stopped further tumor growth and adjuvant treatment after hepatectomy. Liver histological response to neoadjuvant treatment was major or partial (TRG 1-3)
Table 3 Radiological and pathological response to neoadjuvant chemotherapy and description of chemotherapy-related liver complications

\begin{tabular}{|c|c|c|c|}
\hline \multirow[b]{2}{*}{ Radiological response (RECIST) } & \multirow[b]{2}{*}{$C R$} & \multicolumn{2}{|c|}{$N=44$} \\
\hline & & 0 & $0 \%$ \\
\hline & PR & 27 & $61 \%$ \\
\hline & SD & 12 & $27 \%$ \\
\hline & PD & 1 & $2 \%$ \\
\hline & n.a. & 4 & $9 \%$ \\
\hline \multirow[t]{5}{*}{ Pathological response ${ }^{a}$} & TRG 1 & 1 & $2 \%$ \\
\hline & TRG 2 & 12 & $27 \%$ \\
\hline & TRG 3 & 10 & $23 \%$ \\
\hline & TRG 4 & 17 & $39 \%$ \\
\hline & TRG 5 & 4 & $9 \%$ \\
\hline \multirow[t]{12}{*}{ Chemotherapy-related liver injury } & Steatosis & 26 & $59 \%$ \\
\hline & Minimal & 3 & \\
\hline & Grade 1 & 17 & \\
\hline & Grade 2 & 2 & \\
\hline & Grade 3 & 4 & \\
\hline & SOS & 17 & $39 \%$ \\
\hline & Grade 1 & 11 & \\
\hline & Grade 2 & 6 & \\
\hline & Fibrosis & 16 & $36 \%$ \\
\hline & $\mathrm{F} 1$ & 14 & \\
\hline & F2 & 2 & \\
\hline & Steatohepatitis & 15 & $11 \%$ \\
\hline
\end{tabular}

$C R$ Complete response; $P R$ partial response; $S D$ Stable disease; $P D$ Progressive disease; $n . a \mathrm{~N}$

ot assessed; TRG Tumor regression grade; SOS Sinusoidal

obstruction syndrome.

a Pathological response according to Rubbia-Brandt et al. ${ }^{13}$ with report of the worst TRG score in case of multiple metastases with discordant response between lesions

in 23 patients (52\%). Analysis of the non-tumoral liver parenchyma showed chemotherapy-related complications in 36 patients (81\%) (Table 3 ). The R0 resection rate was $61 \%$.

Primary tumor response assessment according to Mandard revealed 7\% (3/41) of major responses (TRG $1-2), 15 \%(6 / 41)$ of TRG 3 and $66 \%$ of poor response (TRG 4-5). Tissue for TRG analysis was not available in 5 (12\%) patients. TNM stage was as following: 1 ypT0, 1 yрT1, 5 yрT2, 23 yрT3, 7 урT4. There were 10 ypN0, 17 ypN1, 10 ypN2. R0 resection was achieved in 35 patients (95\%). Tissue for TNM analysis was not available in 4 patients (10\%).

\section{Survival}

Median follow-up from time of diagnosis was 30.5 months. On an intention-to-treat basis, median OS from time of diagnosis was 50 months (95\% CI 42-58), as shown in Fig. 1. 


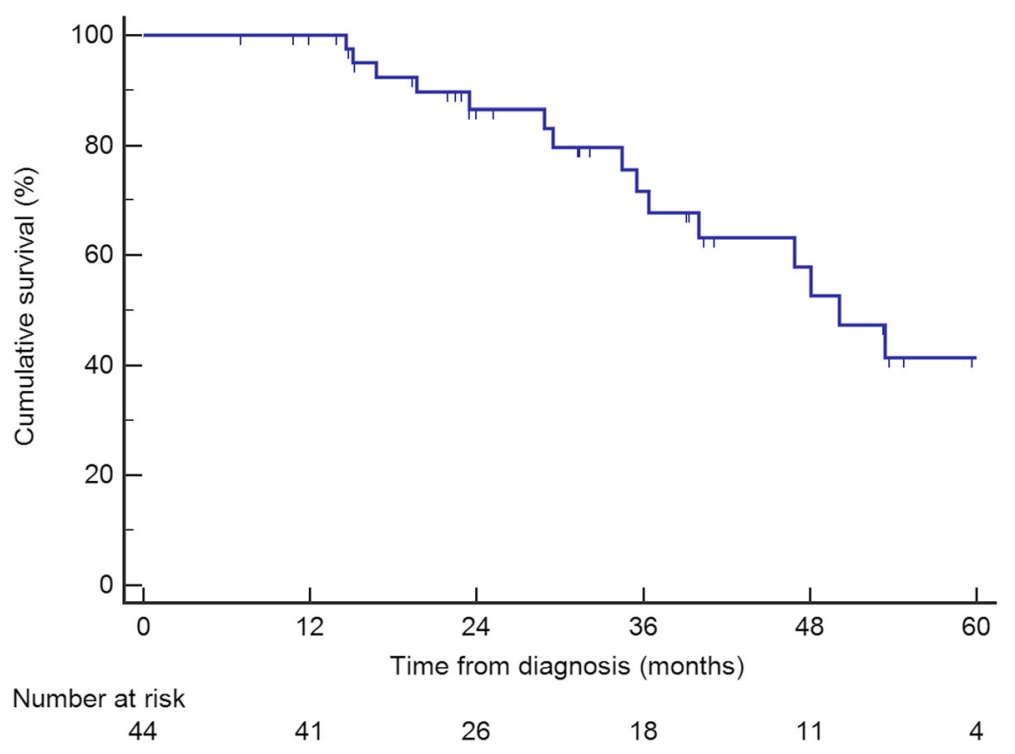

Fig. 1 Overall survival from time of diagnosis of all patients who underwent liver resection for colorectal liver metastases as part of a reverse treatment

Median DFS from time of primary tumor resection was 10 months (95\% CI 5-15), as shown in Fig. 2.

\section{Discussion}

This cohort study of patients undergoing liver-first approach for advanced synchronous CRLM revealed a high completion rate with $93 \%$ of patients who underwent the whole treatment sequence until primary tumor resection. The radiological tumor response rate showed $88 \%$ of partial response and stable disease according to RECIST criteria, and the pathological tumor response was $52 \%$ of major or partial response (TRG 1-3). A promising median overall survival of 50 months, with a 3 -year overall survival of $59 \%$ was observed.

The completion rate of $93 \%$ in the present study was even higher than described in previous series (65 and 84\%) [17-20]. Feared colonic complications such as occlusion or perforation during neoadjuvant treatment occurred only in $11 \%$ of the patients and did not preclude the completion of the whole sequence provided complications were adequately treated. The rates of colonic complications found in the literature ranged between 5

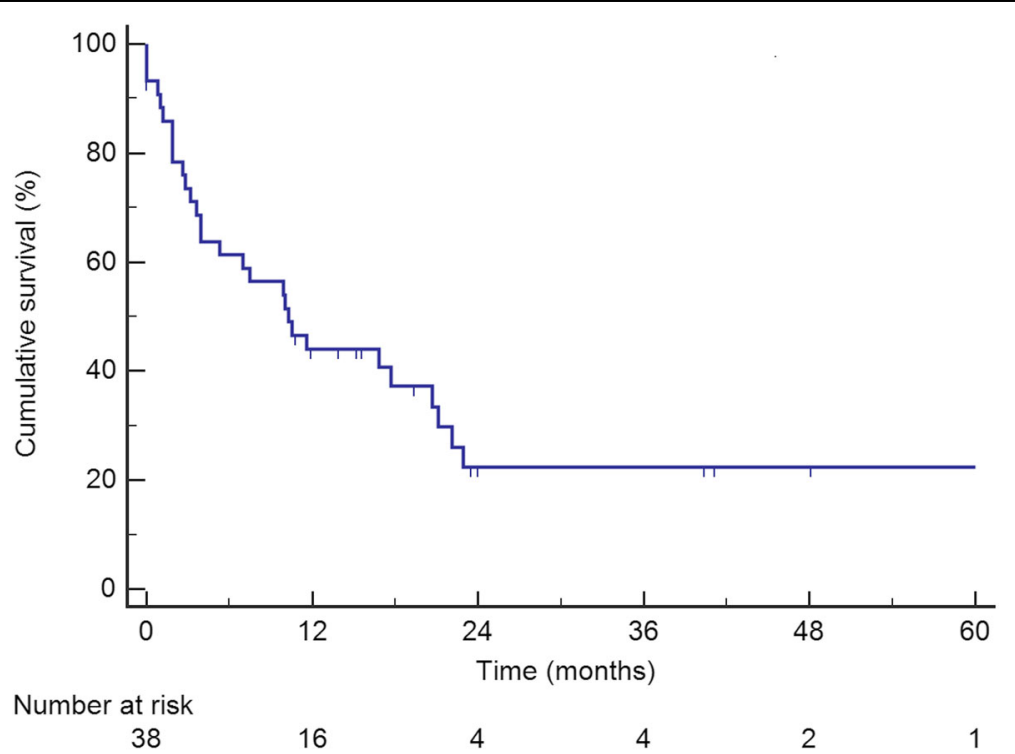

Fig. 2 Disease-free survival from the time of primary tumor resection of patients who underwent liver resection for colorectal liver metastases as part of a reverse treatment 
and $7 \%[17,20]$. Liver surgery was associated with a $52 \%$ morbidity, including 32\% major complications. Previous studies reported morbidity ranging from 17 to $45 \%$ [18, 21-28], and major complication rates were 0 to $27.3 \%$ when reported [19, 22-26]. Our high complication rate could be explained by the aggressive surgical strategy for patients with high oncologic burden with $40 \%$ portal vein embolization and $61 \%$ major hepatectomies, compared to $11-60 \%$ portal vein embolization $[18,21,22$, $28,29]$ and $36-89 \%$ major hepatecomies [18-20, 22-26, $29,30]$ in other reports. However, there was no mortality within 90 postoperative days, while the highest reported mortality rate of $2 \%$ in the series from Welsh et al. [19]. Morbidity after colorectal resection was $39 \%$ in the present study, with $15 \%$ major complications, concordant with other series reporting 16.7 to $44.4 \%$ overall morbidity [23, 24, 26].

Radiological response of CRLM to neoadjuvant treatment was predominantly partial response (61\%), followed by stable disease (27\%). These results were similar to those found in the literature with 3 studies reporting 5-8\% complete response, $68-83 \%$ partial response, $0-30 \%$ stable disease and $8 \%$ progressive disease $[18,26,30]$. Pathological response of CRLM to neoadjuvant treatment was major or partial (TRG 13 ) in more than half of the patients (52\%). A previous study also reported the histological response rate among patients undergoing reverse approach, with 93\% (27/29) of TRG 1-3 [31]. The lower histological response observed in the present study is difficult to compare as various regimens of neodajuvant chemotherapies were used because of referred cases. Histological response of the primary tumors were major (TRG 1-2) in 7\% and poor (TRG 4-5) in 66\%, compared to $35 \%$ in each group in the study of Gervaz et al. with standardized chemotherapy [31]. R0 resection was achieved in $61 \%$ of the patients, which is comparable with other studies reporting compete resection rates of $50-80 \%[18,26,27,32]$.

The OS rates were 59 and $39 \%$ at 3 and 5 years, respectively, with a median OS of 50 months. These results were in line with other reports, with a 3 and 5-year OS of 30 to $89 \%$ and 30 to $72 \%$, respectively [19, 21-24, 26, $27,30,33]$. Nine studies compared the outcomes of reverse and classical treatments with similar results in both groups regarding OS. However these findings need to be balanced with the fact that there were significantly more liver metastases [19, 22, 26], larger lesions [27, 28] and more bilobar spread in the liver-first group [25]. Nevertheless, two studies showed similar OS in both groups after propensity score matching [27, 29]. The DFS at 3 years was $25 \%$ in the present study, which is comparable with DFS rates reported in the literature, ranging from 0 to $31 \%[18,26,27,33]$.
Among limitations, the retrospective analysis of prospectively collected data in a single institution presents its inherent risks of bias of patient selection, missing data, and loss to follow up. Patients included in the reverse treatment were highly selected and only patients who underwent liver resection for synchronous CRLM before removal of the primary tumor were included. Moreover, as a tertiary referral center, some patients were addressed from other centers after favorable response to chemotherapy. Accordingly, data on patients with intention to reverse approach but who failed to undergo liver resection were missing. In the same way, the exact number of patients who were initially considered as unresectable and who presented a significant response allowing a liver resection was not available. Despite patients' heterogeneity in terms of chemotherapy regimens or tumor burden, no subgroup analysis was performed due to the limited number of patients. The main weakness of such a study is the absence of control group. However, as $75 \%$ of liver metastasis were unresctable initially, the only real control group should not be patient with "classical" treatment sequence (colon first), but patients with palliative chemotherapy only. Similar observation may be done on other series $[19,22$, 26-28], with some cases of smaller liver metastasis allowing to choose between reverse or classical treatment, which was not the case in the present series.

\section{Conclusions}

In conclusion, the reverse treatment is safe and feasible with a high rate of patients undergoing the whole process. With high rate of tumor response during chemotherapy, the reverse approach allows resection of both liver and pulmonary metastases, as well as resection of the primary tumor, with a promising long-term survival for highly selected patients with advanced synchronous colorectal liver metastases. Therefore, patients with synchronous colorectal liver metastases, even with initially unresectable disease, should be discussed in multidisciplinary board to assess the feasibility of such a reverse treatment.

\footnotetext{
Abbreviations

CCl: Comprehensive complication index; CEA: Carcino embryogenic antigen; CRLM: Colorectal liver metastases; DFS: Disease-free survival; FRL: Future remnant liver; LAR: Low anterior resection; OS: Overall survival; RECIST: Response evaluation criteria in solid tumor; SOS: Sinusoidal obstruction syndrome; TRG: Tumor regression grade

\section{Acknowledgements}

Not applicable.

\section{Authors' contributions}

CDP and DR contributed equally to the study conception and design, to acquisition and analysis of the data, as well as drafting of the manuscript. MS and ND were major contributors in the study conception and in writing the manuscript. $\mathrm{NH}$ was a major contributor to the study conception and critically reviewed the manuscript. PB analyzed all radiological data and
} 
critically reviewed the manuscript. CS and CR reviewed the histological data and contributed in writing the manuscript. MM analyzed the oncological data and critically reviewed the manuscript. All authors read and approved the final manuscript.

\section{Funding}

No funding was received for the present study.

\section{Availability of data and materials}

The datasets generated and/or analysed during the current study are not publicly available due to the terms agreed with the local ethics committee with full access restricted to CDP and DR. They are available from the corresponding author on reasonable request.

\section{Ethics approval and consent to participate}

This study was approved by the local ethics committee, Commission cantonale (VD) d'éthique de la recherche sur l'être humain, CER-VD, protocol Number 2016-01286. Written informed consent was obtained from all individual participants included in the study.

\section{Consent for publication}

Not applicable.

\section{Competing interests}

The authors declare that they have no competing interests.

\section{Author details}

'Department of Visceral Surgery, Lausanne University Hospital (CHUV) University of Lausanne, Rue du Bugnon 46, 1011 Lausanne, Switzerland. ${ }^{2}$ Department of Radiology, Lausanne University Hospital (CHUV), University of Lausanne, Rue du Bugnon 46, 1011 Lausanne, Switzerland. ${ }^{3}$ Department of Pathology, Lausanne University Hospital (CHUV), University of Lausanne, Rue du Bugnon 46, 1011 Lausanne, Switzerland. ${ }^{4}$ Department of Medical Oncology, Lausanne University Hospital (CHUV), University of Lausanne, Rue du Bugnon 46, 1011 Lausanne, Switzerland.

\section{Received: 21 August 2019 Accepted: 6 April 2020}

\section{Published online: 19 April 2020}

\section{References}

1. Leporrier J, Maurel J, Chiche L, Bara S, Segol P, Launoy G. A populationbased study of the incidence, management and prognosis of hepatic metastases from colorectal cancer. Br J Surg. 2006:93(4):465-74.

2. Pawlik TM, Schulick RD, Choti MA. Expanding criteria for Resectability of colorectal liver metastases. Oncologist. 2008;13(1):51-64.

3. Klinger M, Tamandl D, Eipeldauer S, Hacker S, Herberger B, Kaczirek K, et al. Bevacizumab improves pathological response of colorectal cancer liver metastases treated with XELOX/FOLFOX. Ann Surg Oncol. 2010;17(8):2059-65.

4. Nordlinger B, Sorbye H, Glimelius B, Poston GJ, Schlag PM, Rougier P, et al. Perioperative chemotherapy with FOLFOX4 and surgery versus surgery alone for resectable liver metastases from colorectal cancer (EORTC intergroup trial 40983): a randomised controlled trial. Lancet. 2008; 371(9617):1007-16.

5. Suenaga M, Fujimoto $Y$, Matsusaka S, Shinozaki E, Akiyoshi T, Nagayama S, et al. Perioperative FOLFOX4 plus bevacizumab for initially unresectable advanced colorectal cancer (NAVIGATE-CRC-01). OncoTargets Ther. 2015;8: 1111-8.

6. Loupakis F, Cremolini C, Masi G, Lonardi S, Zagonel V, Salvatore L, et al. Initial therapy with FOLFOXIRI and bevacizumab for metastatic colorectal cancer. N Engl J Med. 2014;371(17):1609-18.

7. Tabernero J, Van Cutsem E, Díaz-Rubio E, Cervantes A, Humblet Y, André T, et al. Phase II trial of cetuximab in combination with fluorouracil, leucovorin and oxaliplatin in the first-line treatment of metastatic colorectal cancer. J Clin Oncol Off J Am Soc Clin Oncol. 2007;25(33):5225-32.

8. Mentha G, Majno PE, Andres A, Rubbia-Brandt L, Morel P, Roth AD. Neoadjuvant chemotherapy and resection of advanced synchronous liver metastases before treatment of the colorectal primary. Br J Surg. 2006;93(7): 872-8.

9. Kelly ME, Spolverato G, Lê GN, Mavros MN, Doyle F, Pawlik TM, et al. Synchronous colorectal liver metastasis: a network meta-analysis review comparing classical, combined, and liver-first surgical strategies: synchronous colorectal liver metastasis. J Surg Oncol. 2015:111(3):341-51.

10. Eisenhauer EA, Therasse P, Bogaerts J, Schwartz LH, Sargent D, Ford R, et al. New response evaluation criteria in solid tumours: revised RECIST guideline (version 1.1). Eur J Cancer. 2009:45(2):228-47.

11. Dindo D, Demartines N, Clavien P-A. Classification of surgical complications: a new proposal with evaluation in a cohort of 6336 patients and results of a survey. Ann Surg. 2004;240(2):205-13.

12. Slankamenac K, Graf R, Barkun J, Puhan MA, Clavien P-A. The comprehensive complication index: a novel continuous scale to measure surgical morbidity. Ann Surg. 2013;258(1):1-7.

13. Rubbia-Brandt L, Giostra E, Brezault C, Roth AD, Andres A, Audard V, et al. Importance of histological tumor response assessment in predicting the outcome in patients with colorectal liver metastases treated with neoadjuvant chemotherapy followed by liver surgery. Ann Oncol Off J Eur Soc Med Oncol. 2007;18(2):299-304

14. Rubbia-Brandt L. Severe hepatic sinusoidal obstruction associated with oxaliplatin-based chemotherapy in patients with metastatic colorectal cancer. Ann Oncol. 2004:15(3):460-6.

15. Bedossa P, Poynard T. An algorithm for the grading of activity in chronic hepatitis C. the METAVIR cooperative study group. Hepatol Baltim Md. 1996; 24(2):289-93.

16. Mandard AM, Dalibard F, Mandard JC, Marnay J, Henry-Amar M, Petiot JF, et al. Pathologic assessment of tumor regression after preoperative chemoradiotherapy of esophageal carcinoma. Clinicopathologic Correlations Cancer. 1994;73(11):2680-6.

17. Lam WWT, Laurence JM, Pang T, Johnston E, Hollands MJ, Pleass HCC, et al A systematic review of a liver-first approach in patients with colorectal cancer and synchronous colorectal liver metastases. HPB. 2014;16(2):101-8.

18. Tanaka K, Murakami T, Matsuo K, Hiroshima Y, Endo I, Ichikawa Y, et al. Preliminary results of "liver-first" reverse management for advanced and aggressive synchronous colorectal liver metastases: a propensity-matched analysis. Dig Surg. 2015;32(1):16-22

19. Welsh FKS, Chandrakumaran K, John TG, Cresswell AB, Rees M. Propensity score-matched outcomes analysis of the liver-first approach for synchronous colorectal liver metastases. Br J Surg. 2016:103(5):600-6.

20. Sturesson C, Valdimarsson VT, Blomstrand E, Eriksson S, Nilsson JH, Syk I, et al. Liver-first strategy for synchronous colorectal liver metastases - an intention-to-treat analysis. HPB. 2017;19(1):52-8.

21. Mentha G, Roth AD, Terraz S, Giostra E, Gervaz P, Andres A, et al. "Liver first" approach in the treatment of colorectal cancer with synchronous liver metastases. Dig Surg. 2008;25(6):430-5.

22. Brouquet A, Mortenson MM, Vauthey J-N, Rodriguez-Bigas MA, Overman MJ, Chang GJ, et al. Surgical strategies for synchronous colorectal liver metastases in 156 consecutive patients: classic, combined or reverse strategy? J Am Coll Surg. 2010;210(6):934-41.

23. de Jong MC, van Dam RM, Maas M, Bemelmans MHA, Olde Damink SWM, Beets $G L$, et al. The liver-first approach for synchronous colorectal liver metastasis: a 5-year single-Centre experience. HPB. 2011;13(10):745-52.

24. de Rosa A, Gomez D, Hossaini S, Duke K, Fenwick SW, Brooks A, et al. Stage IV colorectal cancer: outcomes following the liver-first approach. J Surg Oncol. 2013;108(7):444-9

25. Mayo SC, Pulitano C, Marques H, Lamelas J, Wolfgang CL, de Saussure W, et al. Surgical management of patients with synchronous colorectal liver metastasis: a multicenter international analysis. J Am Coll Surg. 2013;216(4): 707-16 discussion 716-8.

26. Okuno $M$, Hatano $E$, Kasai $Y$, Nishio $T$, Seo $S$, Taura $K$, et al. Feasibility of the liver-first approach for patients with initially unresectable and not optimally resectable synchronous colorectal liver metastases. Surg Today. 2016;46(6): $721-8$.

27. Lim C, Doussot A, Osseis M, Salloum C, Gomez Gavara C, Compagnon P et al. Primary tumor versus liver-first strategy in patients with stage IVA colorectal Cancer: a propensity score analysis of long-term outcomes and recurrence pattern. Ann Surg Oncol. 2016;23(9):3024-32.

28. Esposito F, Lim C, Sa Cunha A, Pessaux P, Navarro F, Azoulay D, et al. Primary tumor versus liver-first approach for synchronous colorectal liver metastases: an association Française de Chirurgie (AFC) multicenter-based study with propensity score analysis. World J Surg. 2018;42(12):4046-53.

29. Vallance AE, van der Meulen J, Kuryba A, Charman SC, Botterill ID, Prasad KR, et al. The timing of liver resection in patients with colorectal cancer and synchronous liver metastases: a population-based study of current practice 
and survival. Colorectal Dis Off J Assoc Coloproctology G B Irel. 2018;20(6): 486-95.

30. Verhoef $C$, van der Pool AEM, Nuyttens JJ, Planting AST. Eggermont AMM, de wilt JHW the "liver-first approach" for patients with locally advanced rectal cancer and synchronous liver metastases. Dis Colon Rectum. 2009; 52(1):23-30.

31. Gervaz P, Rubbia-Brandt L, Andres A, Majno P, Roth A, Morel P, et al. Neoadjuvant chemotherapy in patients with stage IV colorectal cancer: a comparison of histological response in liver metastases, primary tumors, and regional lymph nodes. Ann Surg Oncol. 2010;17(10):2714-9.

32. Reding D, Pestalozzi BC, Breitenstein S, Stupp R, Clavien P-A, Slankamenac K, et al. Treatment strategies and outcome of surgery for synchronous colorectal liver metastases. Swiss Med Wkly. 2017;05(147):w14486.

33. Andres A, Toso C, Adam R, Barroso E, Hubert C, Capussotti L, et al. A survival analysis of the liver-first reversed management of advanced simultaneous colorectal liver metastases: a LiverMetSurvey-based study. Ann Surg. 2012; 256(5):772-8 discussion 778-9.

\section{Publisher's Note}

Springer Nature remains neutral with regard to jurisdictional claims in published maps and institutional affiliations.

Ready to submit your research? Choose BMC and benefit from:

- fast, convenient online submission

- thorough peer review by experienced researchers in your field

- rapid publication on acceptance

- support for research data, including large and complex data types

- gold Open Access which fosters wider collaboration and increased citations

- maximum visibility for your research: over $100 \mathrm{M}$ website views per year

At $\mathrm{BMC}$, research is always in progress.

Learn more biomedcentral.com/submissions 